\title{
Acotaciones al costumbrismo peruano
}

Una de las manifestaciones de la escuela romántica fué la creación de una literatura nacional, con el medio ambiente, la leyenda y el paisaje nativos, lo cual dió como resultado un género literario nuevo que se llamó costumbrismo.

En España, según Clifford Marvin Montgomery, las costumbres de este país ya figuraban en los escritos de los autores satíricomoralistas y novelistas del siglo xvI, ${ }^{1}$ pero la literatura costumbrista propiamente dicha no aparece hasta bien entrado el siglo XIX cuando escritores como Serafín Estébanez Calderón ("E1 Solitario"), Ramón Mesonero Romanos ("E1 Curioso Parlante”) y Mariano José de Larra ("Fígaro"), comenzaron a publicar sus artículos y cuadros de costumbres.

Un cuadro de costumbres es un ensayo o bosquejo corto que presenta los diferentes aspectos de la vida contemporánea del autor. En estos cuadros casi no hay trama ni interés en los personajes; toda la atención está concentrada en el medio ambiente, pintoresco, gracioso o peculiar.

Mesonero Romanos y Larra esconden tras de sus cuadros de costumbres un fin moral, social o político, con miras de reforma y educación. Estébanez Calderón no se preocupa de la finalidad moral, solamente presenta lo que le rodea: para él "lo más importante es la escena misma, no los tipos; las costumbres, no los actores". ${ }^{2}$

El cuadro de costumbres llegó a su apogeo en España en 184344, cuando un grupo de más de cincuenta escritores publicó una colección de estos cuadros bajo el título de Los españoles pintados por sí mismos. Esta colección fué de gran trascendencia para muchos países hispanoamericanos porque despertó en los escritores el deseo 
de hacer lo mismo con los personajes y costumbres nativos, dando como resultado las publicaciones: Los mexicanos pintados por si mismos, Los cubanos pintados por si mismos, etc.

El cuadro de costumbres, como género, llega a la América latina durante los albores del romanticismo, y los escritores americanos comienzan imitando a los costumbristas españoles, pero muy pronto el cuadro de costumbres americano adquiere características propias: los temas, los personajes y el paisaje, naturalmente, son americanos y las descripciones son más detalladas y más realistas. El criollismo y el regionalismo, que surgen más tarde, tienen sus raíces en el cuadro de costumbres.

Por medio de las obras costumbristas se dieron a conocer, por primera vez al público en general, muchas de las costumbres pintorescas de diferentes regiones aisladas, el modo de vivir de las diferentes capas sociales, y la provincia. Los habitantes de una región supieron cómo vivían sus compatriotas en otras regiones. México y Colombia fueron los países donde más se cultivó este género literario.

Algunos escritores satirizan las costumbres y a los personajes que les rodean, ya sea con una sátira benigna y humorística, ya sea con una sátira cortante y flageladora, mientras que otros usan el tono serio y narrativo para sus descripciones.

En el Perú, el costumbrismo surge antes del advenimiento del romanticismo y se diferencia del de otros países por su característica satírica y por su centralización en la ciudad de Lima. No es sino pasado mucho tiempo después de su comienzo cuando las costumbres de las provincias atraen la atención de los escritores peruanos.

Para poder entender mejor las razones de esta diferencia entre el costumbrismo peruano y el de otros países, es necesario conocer algo de las corrientes ideológicas que chocaban cuando apareció este género literario.

\section{Corrientes ideológicas en el Perú,} AL APARECER EL COSTUMBRISMO

En el Perú, y sobre todo en Lima, sede del Virreinato, la adhesión a la corona española estaba fuertemente arraigada. La aristocracia llevaba una vida regalada, el clero era muy fuerte y los indios y negros esclavos les proporcionaban las comodidades y el bienestar. 
No todos estaban satisfechos con este estado de cosas; había criollos que resentían la dominación española y se incubó el movimiento que ansiaba la emancipación. Pero este movimiento no era lo suficientemente fuerte para poder lograr la independencia por sí solo, y tuvieron que acudir a la ayuda de los ejércitos de San Martín y a los de Bolivar que rompieron el lazo entre España y el Perú.

Después de proclamada la Independencia, la mayoría de los criollos que participaron en ella quiso continuar el régimen económico colonial. Estos criollos hicieron la Revolución, no para el bienestar del país, sino para su propia ganancia. La aristocracia colonial fué suplantada por la aristocracia criolla; los militares se adueñaron del poder; el clero continuó tan fuerte como durante la colonia y las clases oprimidas tan miserables como antes. El Perú era independiente; pero el cuadro social permanecía igual al cuadro social colonial.

En contraste con los que querian perpetuar el régimen económico y social de la colonia, había un grupo que se rebeló contra la nueva aristocracia, que no estaba satisfecha con la dominación militarista, que quería hacer del Perú un país donde la palabra Libertad no fuera una palabra hueca, sino una realidad.

Los adalides de este grupo eran Luna Pizarro, Vigil, Castilla y otros. Estos hombres lucharon contra el espiritu colonial de sus compatriotas, asi como contra el militarismo en el gobierno. Se rebelaron contra el espíritu monárquico de San Martín, contra la constitución vitalicia de Bolivar, contra la dictadura ilustrada de Vivanco, contra la Universidad anticuada y conservadora y contra el feudalismo colonial en la economía.

\section{Costumbrismo en el Perú}

Las costumbres peruanas habían soportado ataques desde tiempos inmemoriales. La copla española traída por los soldados de la conquista se prestaba a la satirización de costumbres, y al mestizarse ridiculiza las costumbres y a los personajes del país. Pero la copla no constituye una literatura costumbrista propiamente dicha, la copla es la literatura popular de la colonia, una literatura espontánea $\mathrm{y}$ en su mayoría anónima.

La literatura costumbrista peruana comienza con el advenimiento de la República. 
Apenas alejado Bolívar del escenario del Perú ... irrumpe la risotada del satírico y la grita del hombre de pasión. La oratoria, la poesía festiva y el periodismo se abalanzan sobre la obra del Libertador. 3

Las revoluciones, la falta de orden, el favoritismo de los numerosos presidentes que se suceden con una velocidad vertiginosa y el militarismo, todo cae bajo la sátira de los escritores peruanos. A través de estas sátiras se ven claramente las dos tendencias ideológicas que predominaban en el Perú : la tendencia autocrática, colonialista y españolizante, está representada por Felipe Pardo y Aliaga y la tendencia liberal, nacionalista, criolla, está representada por Manuel Ascensio Segura.

\section{Manued Ascensio Segura (1805-1871)}

Segura es el abuelo del teatro peruano y representa el principio del criollismo en el Perú. Uno de los numerosos discípulos que se reunieron alrededor de él fué Ricardo Palma, joven aún y quien, según L. A. Sánchez, "aprendió en Segura su inclinación criolla." 4

Segura fué un escritor festivo y satírico. Su sátira era benigna, no escribía para escarmentar sino para retratar la vida y las costumbres de una manera risteña y agradable.

El estilo de sus obras es un poco descuidado. Sus versos a veces eran irregulares. Casi no corregía sus comedias porque "no podía preocuparse de limar un giro o encuadrar un adjetivo cuando la vena festiva lo arrastraba por otros cauces exhaustos, hasta él, de nuestra poesía criolla." "

Veamos cuáles son los diferentes aspectos de la vida limeña que desfilan por las comedias de Manuel Ascensio Segura.

En El sargento Camuto, comedia en un acto estrenada en 1839, se presenta la arrogancia de los militares en Lima, durante el gobierno del presidente Gamarra.

Canuto es el prototipo de estos militares: ignorante, cobarde y arrogante, que se considera superior solamente porque es militar:

¿Vaya, vaya! un militar que ha llegado ya a sargento, no se debe acobardar porque un paisano mugriento se la quiere barajar. ${ }^{6}$ 
Expresa la ventaja de ser militar don Sempronio cuando se queja del hecho de que ningún trabajo da para vivir en el país y de que solamente los militares tienen todas las ventajas. El sentimiento contra los militares está expresado por la rebelión de la muchacha a quien desean casar con Canuto y por los insultos del novio de ésta.

La saya y manto, comedia en tres actos estrenada en 1842, presenta las costumbres durante el gobierno de Santa Cruz. Aquí se pone al descubierto la adulación y el servilismo que había que ejercer para obtener empleos públicos; se presenta el patriotismo hipócrita de los que cambian de casaca, cada vez que cambia el gobierno:
Respeto, amor manifiesto
al que me ofrece un destino;
al que no, lo desopino
cuanto puedo y lo detesto.
La conveniencia es la voz
que rige mi patriotismo...
Lo que yo quisiera es ciencia
para atrapar un buen puesto.
Serví a Obregoso y me dió;
después fuí Salaverrino;
hoy seré Santacrucino;
y mañana... iqué sé yo! 7

Además del aspecto político, encontramos en esta comedia las costumbres que predominaban en aquella época, como el uso de la saya y manto que las limeñas utilizaban para diferentes fines.

$$
\text { ...y en Lima! }
$$

ique, con la saya y el manto,

y ese tapadito de ojo

engañan al mismo diablo! 8

Nos podemos dar cuenta de cómo eran las calles de Lima, cuando un personaje exclama:

$$
\begin{aligned}
& \text { Y luego el tal empedrado } \\
& \text { que parece un puerco espín. } \\
& \text { Yo no sé, niña, en que piensa } \\
& \text { la policía } 9 \text { de aquí. } 10
\end{aligned}
$$

A través de esta comedia llegamos a conocer que existía un censor de obras dramáticas en la ciudad de Lima y las dos preferen- 
cias literarias predominantes: la de los que leían obras traídas del extranjero y criticaban las peruanas sin siquiera haberlas leído o visto, y la de los que querían estimular el arte nativo.

$\tilde{N} a$ Catita, comedia en cuatro actos estrenada en 1856, es la historia de una trotaconventos peruana que se entromete en la vida de todos, de todos aprovecha, enreda los asuntos amorosos y propaga el chisme por la ciudad.

Segura emplea numerosos refranes típicos limeños que dan un sabor delicioso a la comedia.

Se satiriza aquí el deseo de los limeños de parecer extranjeros:

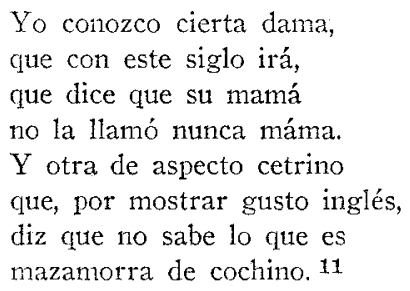

El afrancesamiento está satirizado en la persona de don Alejo que para cada palabra en castellano usa tres en un mal francés.

En Percances de un remitido, comedia en cuatro actos escrita en 1861, al igual que en La saya y manto, se satiriza la política y el gobierno del Perú. Un personaje se lamenta del gobierno, con las siguientes palabras:

$$
\begin{aligned}
& \text { iNo hay un país más desgraciado } \\
& \text { en el mundo que el Perú! } \\
& \text { Aquí se dictan las leyes, } \\
& \text { para que cualquier gandul } \\
& \text { haga de ellas irrisión } \\
& \text { sin miramiento ningún. } \\
& Y \text { aquí cualquier mequetrefe, } \\
& \text { que lee o charla al bultantún } \\
& \text { cuando tiene un destinillo } \\
& \text { o se cruza un biricú } \\
& \text { se vuelve más altanero } \\
& \text { que el mismo Mahomud. } \\
& \text { Y esto nadie lo compone. }{ }^{12}
\end{aligned}
$$

Tenemos una excelente descripción de cómo un ministro desempeña su cargo. El ministro no va a la oficina: 
Los días que no hay despizcho, los que el Ministro está incómodo, los que no va al Ministerio, los que le duele el estómago, los que amalgama elecciones, los que pasa con sus socios, los que emplea en el Consejo, los que atiende al sexo hermoso, los del Correo, del pago, del Vapor y tantos otros... ${ }^{13}$

En esta comedia encontramos también la crítica al periódico "El Comercio" que presenta interés. Este periódico, según la descripción que nos da Jorge Basadre en su Historia de la República del Perú, no pertenecía a ningún bando político. En su sección de "comunicados" se publicaban tanto cosas personales como asuntos doctrinarios. $\mathrm{Y}$ es. precisamente esta sección, de la cual se reproducen párrafos enteros. en el primer acto, la que cae bajo la burla de Segura.

Un personaje que fué tratado mal en uno de estos comunicados, exclama:

Yo no leo jamás eso...

$\mathrm{Ni}$ qué persona decente

se suscribe a tal impreso. 14

Ya es forzoso poner coto

a tan inmundo pasquín. $\mathbf{1 5}$

Nos enteramos por esta comedia de que había gran carestía de la vida durante los últimos años del segundo gobierno de Castilla:

$\mathrm{Y}$ usted ve cóno está el tiempo, plata no más se come hoy, todo se halla por las nubes, ha subido el arroz, y el pan lo han puesto tan chico como bollos de almidón, 16

Es interesante notar lo que usaban las mujeres de esta época:

la una necesita capas, crinolina y pañuelón, la otra zuavo y sobretodo y manteleta de gros, y sombrilla, y abanico y botines de tacón... ${ }^{17}$ 
Las tres viudas, comedia en tres actos estrenada en 1862, nos interesa por las innumerables expresiones puramente limeñas que el autor usa con una gracia excelente. La acción de la comedia no determina ninguna época particular ni hay en ella sátira política ni social.

Manuel Ascensio Segura, de una manera festiva, retrata en sus comedias el descontento de los limeños frente al estado general de cosas en la República peruana. E1 orgullo patriótico de los peruanos y su dolor de ver que la República no se diferencia mucho de la Colonia y que los que están arriba hacen del Perú el hazmerreír de los países extranjeros. Además representa las diferentes costumbres, gustos literarios, tendencias divergentes predominantes, todo un cuadro social de su época.

\section{Felipe Pardo y Aliaga (1806-1868)}

Felipe Pardo y Aliaga representa el polo opuesto al de Segura. Perteneciente a una familia realista, se había educado en España y nunca vió con buenos ojos el advenimiento de la República en el Perú.

Al volver de España después de establecida la República, lleno de principios de disciplina, de lógica y de "despotismo ilustrado", ${ }^{18}$ no puede reconciliarse con el espíritu democrático que hay en el ambiente peruano y la emprende contra todo y contra todos. En sus esćritos se siente la influencia del español Larra. Satiriza con una sátira cortante que se propone herir y escarmentar.

Pardo representa la tradición clásica, la tradición conservadora, la tradición españolizanté. Durante su vida ocupó altos cargos políticos, fué consejero del dictador Salaverry y alrededor de él se congregaron los literatos conservadores de su época.

La primera comedia de Pardo, Frutos de la educación, en que satiriza las costumbres de la República incipiente, produjo un escándalo. Larriva, un español acriollado, que escribía sátiras, tanto contra España como contra el Perú, lo ataca con sus burlas ; Pardo le contesta con palos, y los periódicos limeños recogen el escándalo en sus páginas.

Todas las costumbres limeñas caen bajo la sátira de Pardo. En una poesía titulada "El Carnaval" describe, de una manera casi grotes- 
ca, la costumbre de los limeños de empaparse con agua durante la época del carnaval; las libertades que se toman los hombres con las mujeres, la mezcla de los blancos y los negros en las calles, y expresa: un horror profundo ante tal espectáculo.

Como es natural, en su sátira política se ve claramente su espíritu conservador y antidemocrático. Llama al pueblo:

Rey de aguardiente, de tabaco y daga

a la licencia $y$ al motín propicio... 19

El Colegio Electoral es para él una reunión de "niños, locos, tunantes y borrachos". ${ }^{20}$. Pero donde se desencadena su desaprobación de la República es en el poema satírico "La Constitución Política del Perú", publicado en "El Espejo de mi Tierra", un periódico de costumbres dirigido por el poeta.

Expresa su desdén por la igualdad de los hombres, en el epigrama titulado "A mi hijo en sus días":

Dichoso, hijo mío, tú

Que veintiún años cumpliste;

Dichoso que ya te hiciste

Ciudadano del Perú...

Viendo que ya eres igual

Según lo mandan las leyes

Al negro que unce tus bueyes

$\mathrm{Y}$ al que te riega el maizal. ${ }^{21}$

Pardo ve en el patriotismo y nacionalismo peruanos una cosa absurda; cree al gobierno democrático incapaz de mantener el orden $y$ al pueblo lo considera como una chusma de borrachos, sin principios morales ni aptitud para gobernarse o aprender a gobernar.

\section{Ricardo Palma (1833-1919)}

El doctor E. Herman Hespelt, en An Outline of Spanish American Literature, dice:

There is no doubt that they (las Tradiciones peruanas) are related to the "cuadros de costumbres" in both form and subject matter, but Palma knew how to give his sketches a point of climax which the "cuadros" often lacked and how to draw a character or recreate a whole social era with a few deft lines. 22 
Los escritores costumbristas siempre tratan de las cosas que ven en su derredor, mientras que Ricardo Palma se basó principalmente en la realidad tal como la presentan la historia, la leyenda y las coplas; el resto lo hizo la fantasía. Ricardo Palma es un costumbrista retrospectivo. A través de sus Tradiciones peruanas conocemos muchas de las costumbres del Perú colonial, y aunque algunos autores le niegan autenticidad, debe haber algo de verdad en sus escritos.

Palma usa la sátira, pero es una sátira humorística, benigna, risueña, picaresca, que no hiere demasiado, salvo en casos muy contados.

Entre los personajes satirizados, encontramos escribanos, médicos, virreyes, oficiales del gobierno, agentes de justicia, curas y frailes: es decir, a los que componían las clases privilegiadas de la colonia. Están satirizados también la Iglesia, el Tribunal de la Inquisición, la superstición, los litigios interminables y en grado menor la política de su época.

Su sátira y crítica siempre siguen la misma pauta: siempre se conduele de los oprimidos, presenta a las clases gobernantes como opresoras, a los curas como ignorantes, sensuales y codiciosos. Se puede ver que era liberal, anticlerical y volteriano.

Con don Ricardo Palma se cierra la primera etapa del costumbrismo en el Perú. Esta primera etapa se caracteriza por ser de tendencia satírica y por limitarse a la ciudad de Lima. Leyendo las obras de Segura, Pardo y Aliaga y Ricardo Palma, no se descubre nada de la vida en las provincias, ni siquiera a través de los limeños, con la única excepción de la mención de un pueblo de veraneo en Percances de un remitido, de Segura. Todo el interés está concentrado en la ciudad de Lima, lo cual era un rasgo característico del Perú, hasta que con la llegada del realismo se descubre la provincia y la riqueza del material en asuntos literarios que ella contiene.

Clorinda Matto de Turner introdujo el tema del indio, en su novela Aves sin nido y escribió un libro de cuadros costumbristas que tratan de la provincia; pero el que descentralizó el costumbrismo pertano fué Abelardo M. Gamarra. 
Abelardo M. Gamarra ("E1 Tunante") (1857- )

Gamarra describe la vida de los pueblos chicos de la provincia donde en casas rústicas, calles sin empedrado y sin progreso, viven hombres y mujeres analfabetos en su mayoría. Después de leer Cien años de la vida perdularia, el lector descubre que el Perú es un pueblo apasionado por la política, un pueblo dividido en dos clases: los que están en el poder y los que hacen la oposición, y toda su vida gira alrededor de las luchas de los dos partidos. Los que no toman parte activa en estas luchas sufren las persecuciones de ambos. Gamarra nos dice que el derecho de propiedad había desaparecido; tanto un bando como el otro se apropia de lo ajeno y "... de este modo, como a viajero en despoblado, no dejan camisa al infeliz trabajador." 23

Gamarra ataca este estado de cosas ; enristra contra los politiqueros, las instituciones, la ignorancia y los dirigentes y el bandidaje políticos; en una palabra, contra tođa la organización política peruana, tanto en la provincia como en la capital.

Su sátira es cortante, flageladora, sin compasión. Nos presenta a los politicastros en su aspecto más bajo, más abyecto. A través de la sátira de Cien años de la vida perdularia presenta el modo de vivir provinciano: una vida monótona, ociosa, vacía, sin otras ambiciones que subir al poder o mantenerse en él.

Gamarra es un buen observador; no se le escapa ningún detalle, todo cae bajo su pluma cortante. Escribe para escarmentar; expone las llagas de la sociedad que le rodea, no para reirse de ellas sino con la esperanza de mejorarlas.

La preocupación por los problemas sociales del Perú desaparece con la llegada del Modernismo. Los escritores modernistas se encierran en sus torres de marfil y no quieren ver lo que pasa en su derredor. El costumbrismo, naturalmente, desaparece.

Después surge una serie de escritores que se ocupan solamente de la ciudad de Lima; sienten añoranza por las glorias pasadas, por la vida colonial que había desaparecido para más no volver. 
Desde el año de 1918 comienzan a aparecer obras en que los escritores peruanos muestran de nuevo su preocupación por la vida que les rodea. Lima ya no es el único tema de su creación; todo Perú desfila por las páginas de sus obras.

A partir de este momento, los escritores ya no sólo se ocupan en pintar las costumbres y tipos pintorescos; se dedican a presentar, de una manera realista, la vida de los habitantes del país. Están preocupados por los problemas sociales de las clases oprimidas. Las obras ya no son satíricas ni festivas. Los escritores pintan la tragedia del indio, las injusticias que cometen con él los blancos y mestizos. Casi todos son pesimistas. Presentan la vida trágica del indio para que se conozca, para que se remedie; pero ellos mismos no pueden encontrar la solución al problema.

El género literario que se dedica a presentar la vida y los problemas de los habitantes del país ya no se llama "costumbrismo", ahora se llama "regionalismo". Cada autor se ocupa de la región que le es más conocida.

En el Perú el hecho de que cada escritor se ocupe de la región que mejor conoce es de importancia primordial, ya que el territorio peruano se divide en tres zonas completamente diferentes, con clima, aspecto, habitantes y modo de vivir distintos.

La costa, vista desde el aire, aparece como una larga faja árida, surcada por ríos de trecho en trecho. Solamente al lado de estos rios hay vegetación y poblaciones. El clima es templado y seco, casi sin lluvias. En esta región se encuentran los grandes latifundios algodoneros, las plantaciones de caña de azúcar y de arroz, y los habitantes son blancos, negros, zambos, mulatos y mestizos.

Inmediatamente después de la costa, comienza la sierra en cuya parte más baja se encuentran los valles serranos llamados "temples". El clima es cálido y la producción y la población son semejantes a las de la costa.

A unos 1,500 metros de altura comienza la sierra propiamente dicha. Aquí el clima se vuelve más frío, a medida que se eleva el terreno hasta alcanzar temperaturas muy bajas en la "Puna", la región más alta de la sierra.

Después de los "temples" se entra en lo que se llama "E1 granero" porque allí se cultiva el trigo y la cebada, así como toda clase de vegetales. Después se entra en la región donde crece el pasto 
que tiene por nombre "Jalca", y por último se llega a la "Puna" donde el frío es muy intenso y no hay vegetación. Alli se encuentran los yacimientos de oro y otros minerales.

En la sierra es donde viven los indios y los cholos, que tanto figuran en la literatura peruana contemporánea. En la parte sur y en el centro predominan los indios, mientras que la parte norte está habitada casi exclusivamente por los cholos.

La selva es el declive de los Andes hacia el Amazonas. Es la región más rica y menos explotada. Los ríos son los caminos de la selva y a orillas de ellos se encuentran las pocas poblaciones que hay en la región. El clima es cálido e insalubre. Los habitantes son blancos o mestizos y viven generalmente dedicados a la explotación del caucho. Dentro de la selva virgen todavía hay indios salvajes.

Abraham Valdelomar pinta la vida costeña de Ica, en El caballero Carmelo (1918); Fernando Romero se ocupa de la selva y escribe 12 Novelas de la Selva (1934); Díez Canseco se ocupa del mulato, en sus Estampas mulatas (1938); Enrique López Albújar pinta la vida en la sierra, en sus Cuentos andinos (1920) y Nuevos cuentos: andinos (1937).

\section{Abraham Valdelomar (1888-1919)}

Abraham Valdelomar, el iniciador del cuento criollo, introduce el costumbrismo de la costa, en la literatura peruana. Natural de Ica, una provincia costeña, utiliza su pueblo y los pueblos cercanos como fondo de sus cuentos. Valdelomar no es satírico; sus cuentos están cscritos en una prosa fácil, pulida, con diálogos naturales y con excelentes descripciones de la naturaleza. Generalmente escribe en primera persona y todos sus cuentos tienen un fin imprevisto.

El caballero Carmelo es una colección de dieciséis cuentos, de los cuales solamente cinco pueden considerarse como costumbristas; podrían llamarse cuentos autobiográficos de la infancia. En ellos describe Valdelomar la vida en el pequeño pueblo de Pisco; las magníficas puestas de sol, la playa, las fiestas religiosas que siempre son un acontecimiento en el pequeño pueblo. Presenta las peleas de gallos, la llegada del circo y otros acontecimientos menores de la vida diaria. Pinta la vida triste de los pueblos que lleva al suicidio, y el fanatis- 
mo religioso que no permite que un suicida quede sepultado en el cementerio. Y sobre todo, pinta la vida de familias acomodadas, de hogares dominados por el padre y atendidos por la madre abnegada.

Valdelomar es sentimental y le gusta escoger temas tristes. En casi todos los cuentos hay una muerte o un accidente.

En sus cuentos Valdelomar se limita a describir a los habitantes acomodados del pueblo. No se presenta la tragedia del mulato ni de los demás componentes de las clases oprimidas.

\section{Enrigue López Albújar (1872- ）}

López Albújar actuó como juez en la sierra peruana, donde pudo observar la vida de los indios perseguidos y explotados.

La crueldad, el horror, los sufrimientos, la degeneración del hombre, son los temas que desfilan por los cuentos de Albújar. Sus cuentos andinos son trágicos, pesimistas, casi sin un rayo de esperanza. La inhumana explotación del indio, su vida de trabajo agotador y bestial, siempre bajo el látigo del patrón, siempre en deuda con él, que le impide cambiar de lugar y buscar una vida más fácil y menos abyecta.

A pesar de su simpatía por el indio, López Albújar no lo idealiza. Lo presenta tal como es: lento, impasible, triste, huraño, desconfiado, fatalista, implacable, vengativo y cruel. Dice López Albújar : "El indio es cruel sobre todo. Y la crueldad es una fruición, una sed de goce, una reminiscencia trágica de la selva". ${ }^{24}$ Albújar trata de interpretar el alma de los indios y to hace admirablemente.

E1 estilo de los cuentos es claro, aunque la abundancia de expresiones indígenas y el uso de regionalismos hacen necesario emplear vocabularios especiales, dificultándose así la lectura.

\section{Ciro Alegría (1909- ）}

Otro escritor que ha tratado la sierra peruana, es Ciro Alegría que con sus novelas ha alcanzado fama universal.

Las novelas de Alegría tratan principalmente de la vida de los cholos, ya luchando contra las injusticias con ellos cometidas, ya con la naturaleza salvaje que les rodea. 
En La serpiente de oro (1935), nos pinta Alegría un grupo de cholos balseros que viven en el valle de Calemar, a las orillas del río Marañón. Toda la vida de esta comunidad está regida por el río, que es su amigo porque les da de comer, les sirve de camino para comunicarse con el mundo exterior y, al mismo tiempo, es su enemigo porque inunda la población y les arrebata a los hombres jóvenes y vigorosos.

El tema principal de esta novela es la lucha del hombre con la naturaleza; pero Alegria presenta, además, excelentes paisajes, así como la actitud hacia la vida, de los hombres que viven dominados por el gran río. Otra de las características del libro son las descripciones de las costumbres, las fiestas, la visita anual del cura, los matrimonios, la antipatía hacia la policía y la protección que se dan unos a los otros, frente a la justicia del gobierno. En esta novela, Alegría, mediante un simbolismo excelente, expresa la esperanza de que el cholo sea el porvenir del Perú. El ingeniero limeño Osvaldo Martínez, se aficiona a la vida de Calemar, se acostumbra a la coca y poco a poco pierde el lustre de la capital. Esto parece indicar que con el tiempo el cholo - la raza más fuerte - será el llamado a forjar los destinos del país.

El escenario de Los perros hambrientos (1939) está colocado en las altas montañas, donde el frío muchas veces es un peligro, tanto para el hombre como para los animales. En esta novela se presenta la lucha del hombre con la naturaleza, tanto como del hombre contra el hombre. Ambos se combinan para hacer dura y miserable la vida de los habitantes de la sierra. Un largo período de sequía que impide la cosecha, hace que se mueran las ovejas, que constituyen la industria principal de la región, y convierte a los hombres en bandidos y ladrones. A esto se añade la inhumanidad del hacendado que niega la ayuda a la comunidad, aunque sus trojes estén repletas de comestibles. $\mathrm{Y}$ cuando los comuneros, desesperados por el hambre y por la muerte de sus seres queridos, atacan la hacienda, las balas de los soldados frustran el intento.

Los perros hambrientos es una novela trágica, como todas las de Ciro Alegría. El final del libro se puede interpretar como un rayo de esperanza para las condiciones sociales del Perú. Con la lle- 
gada de las lluvias, los comuneros recobran la esperanza de un tiempo mejor, cuando la vida sea más llevadera, más fácil, con menos sinsabores y más justicia para ellos. El mundo es ancho y ajeno (1941) es la novela más conocida de Alegría. Trata de los medios que emplea un terrateniente, para destruir una comunidad de las. pocas que quedan en la sierra peruana, no porque necesite la tierra, sino para obligar, a los comuneros a trabajar como peones en su hacienda. Aquí encontramos a numerosos personajes de todas las clases sociales: campesinos de la comunidad de Rumi, peones de la hacienda, hacendados, bandidos, cabecillas revolucionarios, abogados poco escrupulosos, empleados públicos, etc. Algunos de los personajes están idealizados, como Rosendo, el alcalde de la aldea y otros habitantes de Rumi, o son exageradamente crueles, como los hacendados y los de su calaña.

Además de presentar la vida de sus personajes, Alegría presenta sus creencias, sus diversiones y su filosofía de la vida.

En El mundo es ancho y ajeno Alegría se propuso - y lo logrópresentar la tragedia del Perú de una manera enérgica y sin temor.

El estilo de las dos primeras novelas es más trabajado y pulido que el de la última. Alegría usa muchos regionalismos en los diálogos, pero esto no dificulta la lectura.

Entre los contemporáneos más jóvenes que se ocupan en pintar la vida de los cholos en la sierra, tenemos a Porfirio Meneses (1915-

), un escritor que promete mucho. Su colección de cuentos llamada Cholerías, pinta los diferentes aspectos, tanto tristes como alegres, de la vida del cholo en la región de Ayacucho. Meneses presenta las dificultades del cholo pobre que con su trabajo trata de mantener su chacrita y su familia; pinta la estricta división de clases; el odio recíproco entre el blanco y el cholo y el de éste hacia el indio. Pinta la crueldad de unos y de otros. Muchos de sus cuentos tratan de amores clandestinos y de la venganza terrible que éstos traen.

Meneses siente y describe magníficamente el paisaje, y su estilo es fácil y vívido. Los cuentos son intensos; el autor no necesita muchas páginas para pintar una tragedia que conmueva intensamente al lector. La injusticia que cometen con el cholo hacendados y funcionarios públicos, está presente en casi todos los cuentos. 


\section{CONCLUSION}

Hasta 1918 el costumbrismo peruano no llegó a tener la trascendencia que este género literario tuvo en otros países latinoamericanos, como México y Colombia, por ejemplo. Sin embargo, debemos tomar en cuenta que los primeros costumbristas peruanos revelaron la psicología y el modo de vivir de este pueblo. A través de ellos conocemos las diferentes reacciones de los peruanos frente a la Independencia.

Por la Tradiciones de Ricardo Palma se conocen muchas leyendas interesantes, el origen de muchos refranes y la vida colonial limeña.

Es de lamentar que los primeros costumbristas se hayan concretado al ambiente limeño, porque de esta manera no captaron el modo de vivir de los provincianos, sus fiestas, sus costumbres, su actitud hacia la Independencia, esto es, el alma de todo un pueblo que tuvo la "suerte" o la "desgracia" de vivir fuera de la Real Cittdad de Lima, capital del virreinato.

Aunque los escritores llamados realistas no produjeron obras costumbristas de importancia, esbozaron por lo menos algunos de los problemas que agitaban la provincia peruana y prepararon el camino al regionalismo, el género que mejor retrata la vida y las luchas sociales del Perú.

Actualmente el cultivo del costumbrismo en el Perú ha tomado mayor impulso, con la nueva promoción de escritores que están revelando el paisaje, las costumbres y los personajes del Perú. Una parte de ella se ha dedicado expresamente al folklore produciendo lo más significativo que hay hasta ahora en la literatura peruana. Entre los nuevos autores, podemos citar a Sergio Quijada, (Estampas huancavelicanas), Colán Secas y Fonseca (Chancay, provincia nuestra), José Mejía Baca (Aspectos criollos), Rómulo Paredes ( $A$ golpe de arpa) y a los de promoción más reciente, cuya obra todavía no se ha recogido en volumen y está desparramada en revistas y peŕiódicos: Donaire Vizarreta, Espinosa Bravo, Mesa Ordóñez, Arturo Muscol, José Eulogio Garrido y Julio Galarreta.

MARY NeMTzow, University of California. Los Angeles. 
$\mathrm{N} O \mathrm{TAS}$ p. 90 .

1 Clifford Marvin Montgomery, Early Costrumbrista Writers in Spain,

2 César Barja, Libros y autores modernos, p. 140.

3 Luis Alberto Sánchez, La literatura del Perí, p. 93.

4 Manuel Ascensio Segura, Comedias, v. 1, p. vI.

5 Ibid., ibid., p. vir.

6 Ibid., ibid., p. 16.

7 Ibid., ibid., p. 57.

8 Ibid., ibid., p. 74.

9 La policía del Municipio del Perú todavía ahora tiene a su cargo la conservación de las calles.

10 Manuel Ascensio Segura, Comedias, v. 1, p. 101.

11 Ibid., ibid., v. 2, p. 7.

12 Ibid., ibid., p. 235.

13 Ibid, ibid, p. 212.

14 Ibid., ibid., p. 142.

15 Ibid., ibid., p. 143.

16 Ibid., ibid., p. 176.

17 Ibid., ibid., p. 176.

18 Luis Alberto Sánchez, La literatura del Perú, p. 95.

19 Felipe Pardo y Aliaga, Poesias, p. 200.

20 Ibid., ibid., p. 201.

21 Ibid., ibid., p. 106.

22 Herman E. Hespelt, et all., An Outline History of Spanish American Literature, pp. 47-48.

23 Abelardo M. Gamarra, Cien años de vida perdularia, p. xvir.

24 Herman E. Hespelt, et all., An Outline of Spanish American Literature, López Albújar, Cómo habla la Coca, p. 718. 